\title{
Laparoscopy Assisted Open Repair of Bilateral Abdominoscrotal Hydrocele in 8 Months Old Baby-Rare Case Report
}

\author{
Kalpesh Onkar Patil, Vaibhav Shah \\ Sevadham Hospital, Talegaon, India \\ Email: dockalpesh@gmail.com
}

How to cite this paper: Patil, K.O. and Shah, V. (2016) Laparoscopy Assisted Open Repair of Bilateral Abdominoscrotal Hydrocele in 8 Months Old Baby-Rare Case Report. Open Journal of Pediatrics, 6, 308315.

http://dx.doi.org/10.4236/ojped.2016.64042

Received: November 17, 2016

Accepted: December 6, 2016

Published: December 12, 2016

Copyright $\odot 2016$ by authors and Scientific Research Publishing Inc. This work is licensed under the Creative Commons Attribution International License (CC BY 4.0).

http://creativecommons.org/licenses/by/4.0/

\begin{abstract}
Bilateral Abdominoscrotal Hydrocele (ASH) is very rare in children and difficult to suspect on clinical examination. Abdominoscrotal hydrocele (ASH) is very unusual presentation of scrotal hydrocele with dumbbell-shaped extension intra abdominally through deep inguinal ring either communicating to peritoneal cavity or non-communicating. No theory can explain exact development of ASH though many theories have been proposed in literature. An abdominoscrotal hydrocele is a congenital pathology involving a scrotal hydrocele expanding through the inguinal canal and reaching the abdominal cavity (pars abdominalis). A simple hydrocele is commonly diagnosed clinically, where as an abdominoscrotal hydrocele is rare and should be differentiated from other cystic lesions of the abdominal cavity in children.
\end{abstract}

\section{Keywords}

Abdominoscrotal Hydrocele, Laparoscopy in ASH, Abdominoscrotal Hydrocele in Children

\section{Introduction}

Herein we report a case of 8 months old baby presenting with bilateral abdominoscrotal hydrocele without any intra-peritoneal connections treated with laparoscopy assisted open approach. The case has been reported with due consent of parents.

\section{Case Report}

A 8 months old boy brought with complaints of bilateral scrotal hydrocele noticed since 5 months gradually increasing in size. On per abdominal examination large lump was 
palpable on left side with both side large scrotal hydrocele present. Ultrasonography of abdomen showed huge cystic swelling on left side of lower abdomen, suspecting retroperitoneal, compressing urinary bladder, communicating with scrotal hydrocele through deep inguinal ring but no intra-peritoneal communication. On right side small cystic swelling noted along the cord structures retroperitoneal along with scrotal hydrocele. Magnetic Resonance imaging (MRI) confirmed the ultrasonography findings with left testis displaced inside intra-abdominal part of cystic swelling and right side testis into the scrotal sac (Figure 1). Surgical repair was scheduled after complete haematological work up of the patient. Under general anaesthesia, with lax abdomen "Springing back ball sign" on left side abdomino-scrotal swelling demonstrated (Figure 2).

Bimanual (scrotal and abdominal) palpation of a large, tense hydrocele identifying one component's enlargement when compressing the other is a manoeuvre which can presume the existence of an ASH [1].

Laparoscopy was performed through an infra-umbilical incision before inguinal canal explorations on either sides. On laparoscopy Urinary bladder was distended with closed right side hernial site with all cord structures entering into inguinal canal. No obvious swelling noted. On left side, large globular cystic swelling retro peritoneal around size $10 \mathrm{~cm} \times 6 \mathrm{~cm}$ noted extending from left hernial site abutting to left lateral wall of urinary bladder (Figure 3). Left hernial site could not be visualised properly. No any internal connections to visceral organs noted on either side. Left inguinal canal is explored as in routine inguinal herniotomy. Evidence of densely adhered cremasteric layer to underlying sac. Hernial sac identified and dissected well from structures surrounding. Cord structures identified posterior to sac densely adhered. After securing cord structures, hernial sac is opened and straw coloured fluid around $90 \mathrm{ml}$ is drained

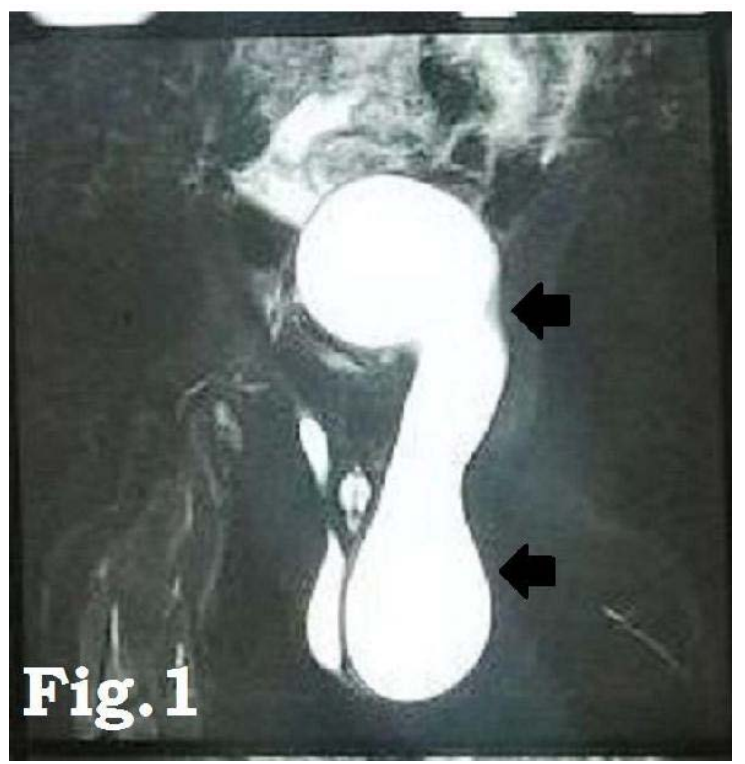

Figure 1. T2-weighted magnetic resonance images from the coronal view. The massive hydrocele extended into the abdomen through the inguinal canal. 


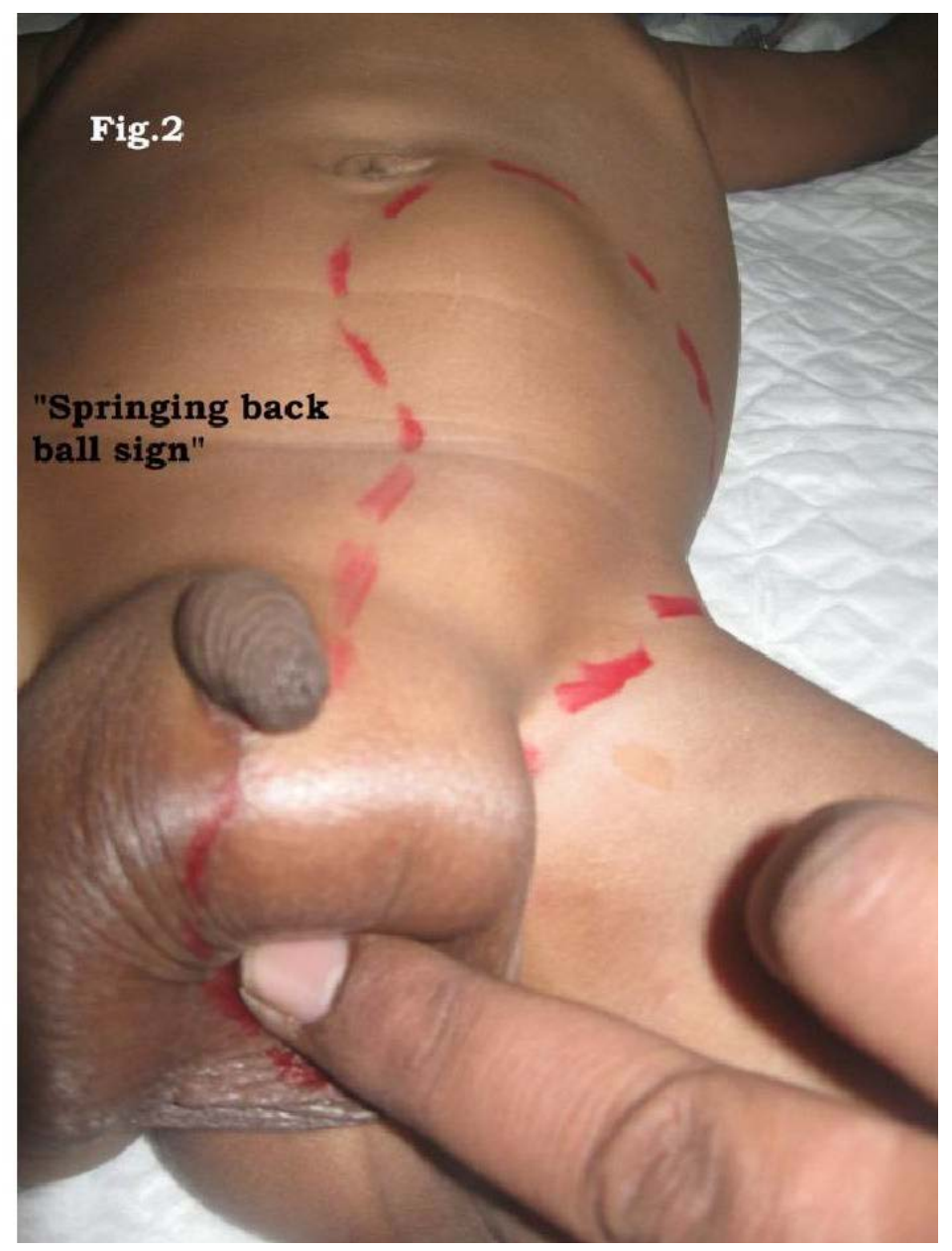

Figure 2. Demonstration of "springing back ball sign".

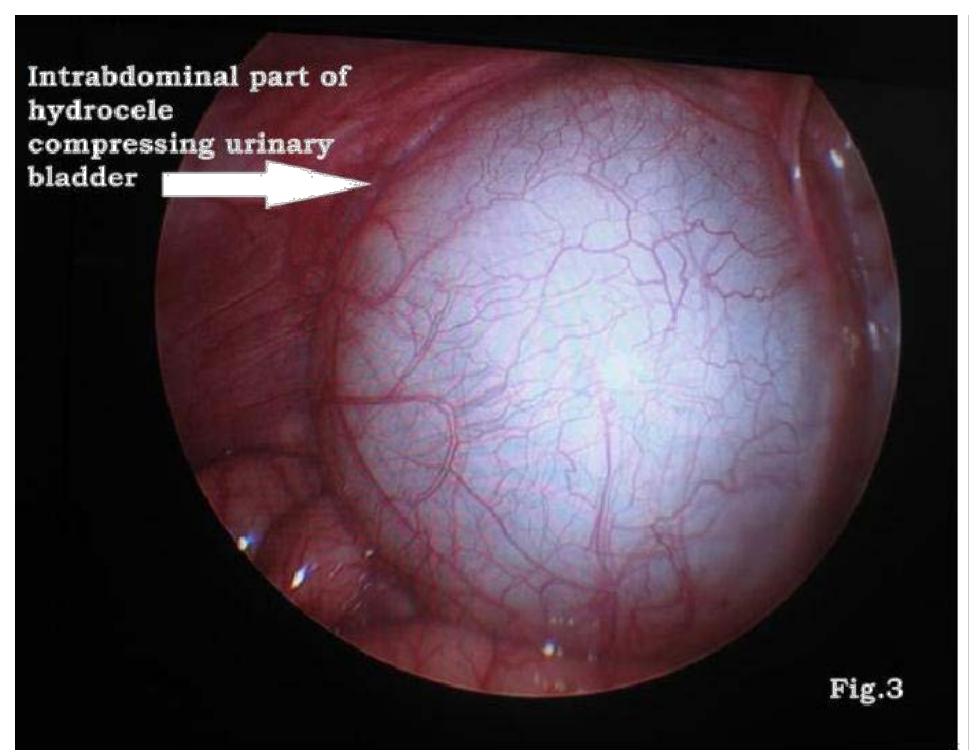

Figure 3. Laparoscopic view of large retroperitoneal cyst near internal inguinal ring. 
out. Intra abdominal extension of sac is dissected by inserting a finger into it (Figure 4), and peritoneal fold swiped back safely without damaging to peritoneum and cord structures. Near total excision of hernial sac done leaving behind streak of part of sac on to cord structures in view of avoiding trauma to vital structures.

Evidence of small sized dysmorphic testis inside the intra abdominal sac (Figure 5), appearance like streak gonad identified. Testis is mobilised up to scrotum and orchidopexy done. Under laparoscopy vision, completely closed left hernial site with cord structures entering in and completely resolved intra abdominal cyst confirmed (Figure 6). On Right side after inguinal canal exploration there was evidence of moderate hydrocele with testis within located in superficial inguinal pouch.

Inversion of sac done with complete drainage of straw coloured fluid. Right side testis normal in size, brought down to right side scrotum and right side orchidopexy done in sub dartos pouch created. Wound closure done in layers. Patient is doing well postoperatively till one year of follow up without any recurrence.

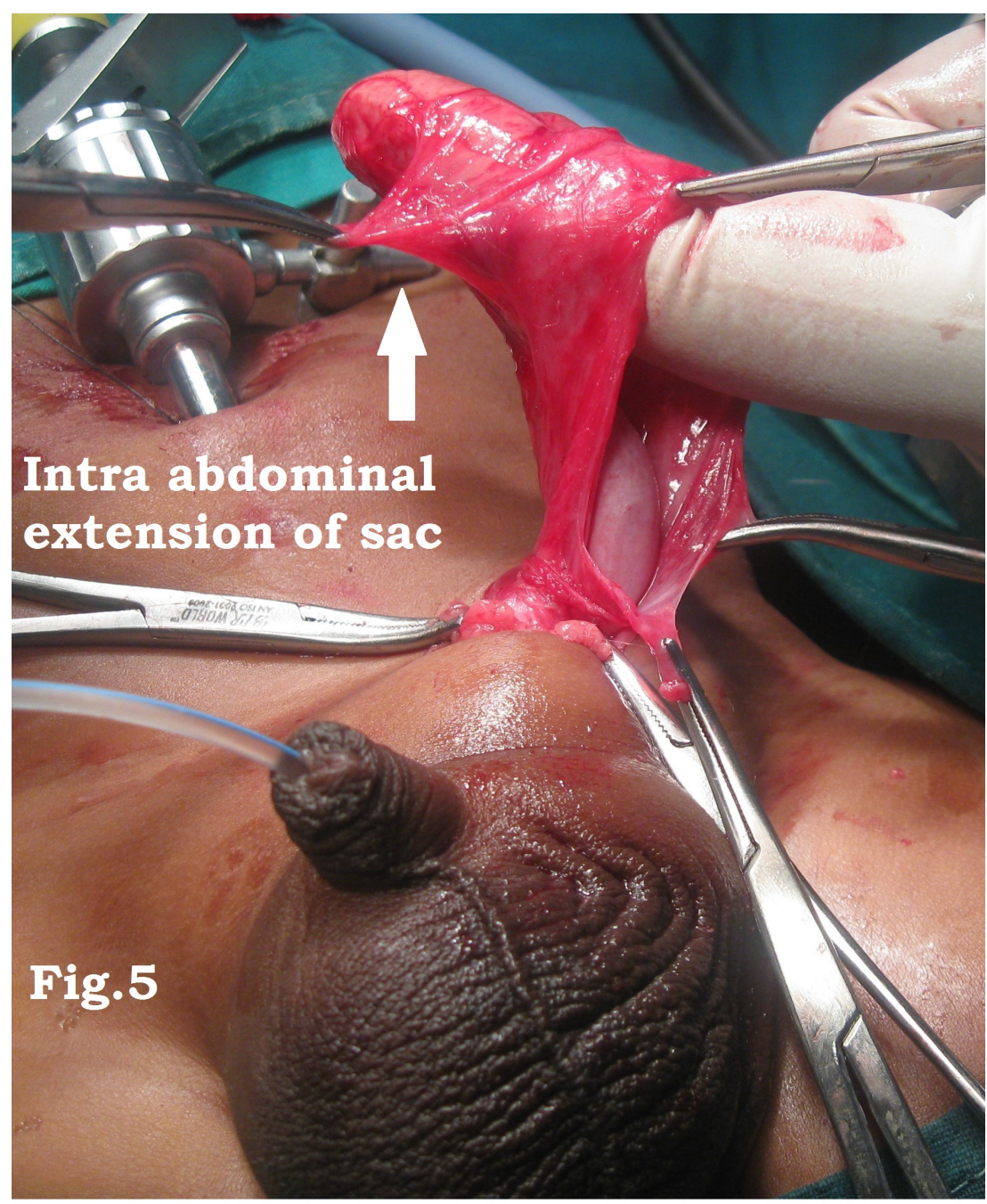

Figure 4. Intra abdominal extension of sac. 


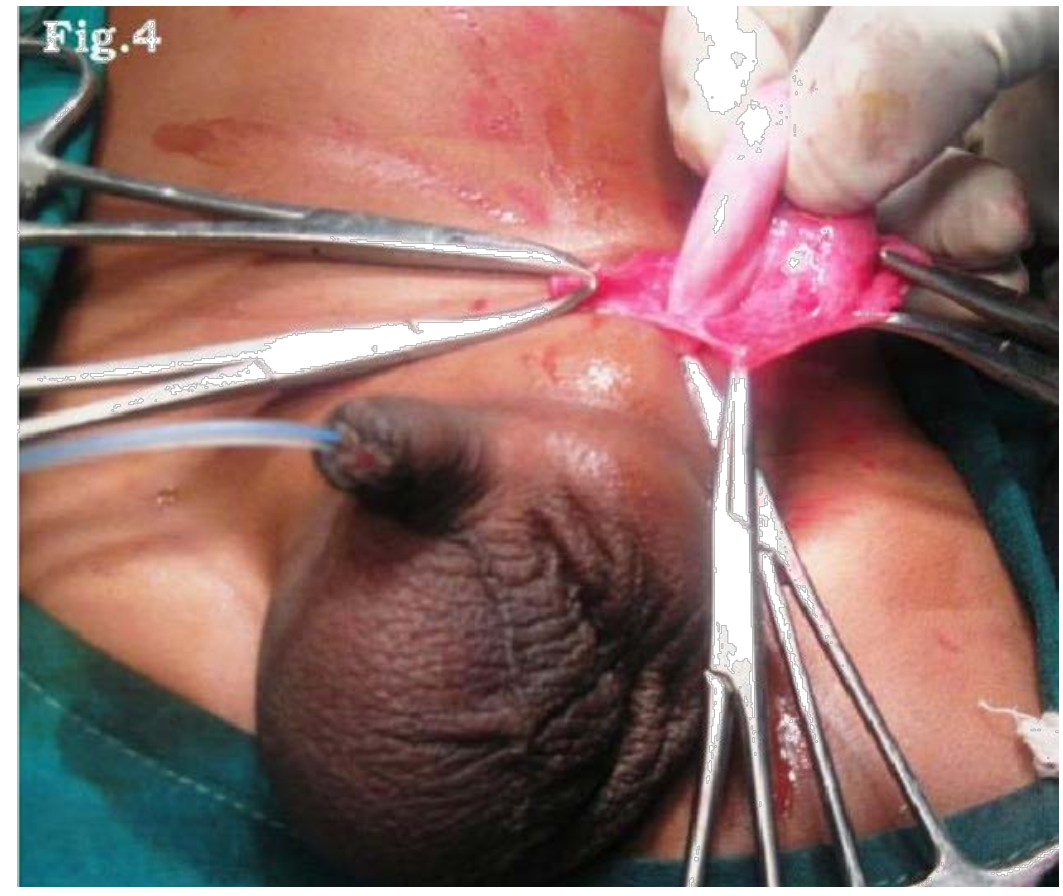

Figure 5. Small sized dysmorphic testis inside the intra abdominal sac.

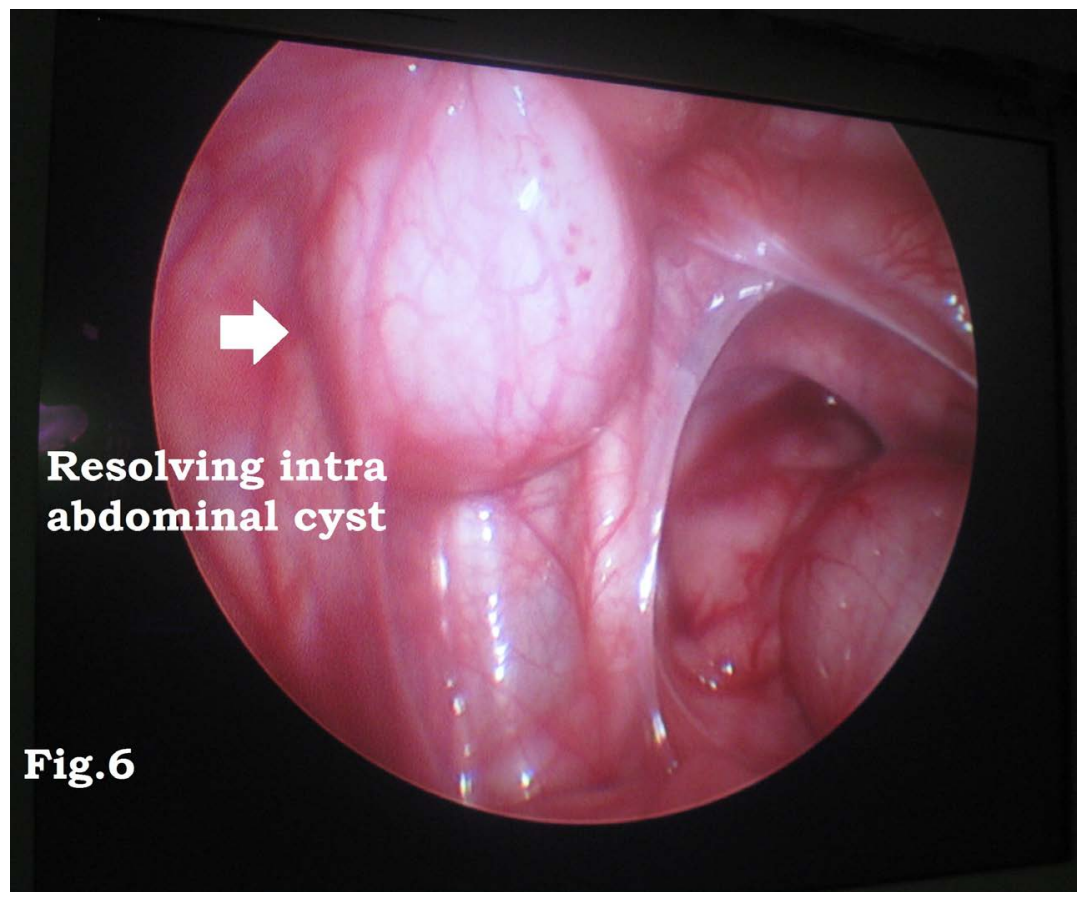

Figure 6. Under laparoscopy vision, closed left hernial site with cord structures entering in and resolving part of intra abdominal cyst confirmed.

\section{Discussion}

Hydroceles are classified into various types depending on the obliteration pattern of the processus vaginalis those may be the hourglass or dumbbell shaped [2]. Etiology of ab- 
dominoscrotal hydrocele (ASH) has been explained in various theories but retroperitoneal positions of the intra-abdominal elements has been reported other than usual properitoneal position [3] [4]. Few assumptions include the existence of a valve-like mechanism in the patent processus vaginalis at the level of internal inguinal ring, a peritoneal diverticulum in the deep inguinal area, or distal expansion of an abdominal hydrocele in the inguinoscrotal space [4]. Careful examination can bring important clues over the nature of hydrocele. Bimanual palpation of a large tensed hydrocele for both abdominal and scrotal components identifying one component's enlargement when compressing the other is a maneuver (Springing back ball sign) which can presume the existence of an ASH.

A simple hydrocele is commonly diagnosed, where as an abdominoscrotal hydrocele is rare and should be differentiated from other cystic lesions of the abdominal cavity in children (Table 1) [2] [3] [4] [5] [6]. ASH's most obvious differential diagnosis is inguinal hernia [4]. Though Diagnosis can be easily confirmed by ultrasound examination, Use of CT or MRI for supplementary evaluation is reported and indicated in the presence of large scrotal hydrocele [4] [7] [8]. Various presentations of ASH such as acute haemorrhagic $\mathrm{ASH}$, a paratesticular malignant mesothelioma of the tunica vaginalis, ASH as a cause of ureterohydronephrosis in infancy have been reported [3] [9] [10].Testicular dyspmorphism has been reported in ASH cases considering increased hydrocele pressure on gonad as a cause [11]. Surgical correction is treatment of choice as soon as ASH is confirmed to prevent compression effect on cord structures and its presumed consequnces [12]. Few cases of spontaneous resolution of ASH and natural remission of the intrabdominal pouch in case of infantile ASH have been reported too [13] [14]. Among various surgical approaches such as paramedian laparotomies or scrotal approach, simple inguinal hydrocelectomy is considered the best choice. Laparoscopic assistance is useful in cases of huge ASH, Bilateral presentations, or non palpable testes [4] [7] [8] [15]. Complete excision of pathogenic tunica vaginalis and drainage of ASH is important to prevent recurrent hydrocele [4] [8]. As very few cases of ASH have been reported till date in pediatric age group, many questions such as etiological factors, delayed effects and choice of surgical approach remain unanswered.

Table 1. Most frequent Cystic lesions in abdomen in boys.
A. Cystic lesions originating from Renal System
B. Cystic lesions originating from Gastro intestinal System
2) Polycystic Renal Disorder.
3) Bladder diverticulum.
1) Mesenteric cyst.
2) Gastrointestinal duplication.
1) Cystic tumor.
C. Cystic lesions with Retroperitoneal origin or Malignancy
2) Lymphangioma.
3) Teratoma.
4) Hamartoma.

1) Large hydronephrosis. 


\section{Conclusion}

Abdominoscrotal hydrocele remains very rare entity in pediatric urology with unclear theories for etiology. The MRI evaluation gives valuable information over the extension of hydrocele and its effect over the underlying structures. Intra-operative gonads evaluation should be done always to rule out dysplasia. Complete excision of pathological processus vaginalis and complete drainage of hydrocele is must to prevent recurrence. Laparoscopy assistance can help in confirming complete excision and drainage of ASH and drainage of isolated intra abdominal retroperitoneal component of ASH.

\section{References}

[1] Blevrakis, E., Anyfantakis, D.I. and Sakellaris, G. (2011) Abdominoscrotal in a 9-Month Old Infant. Hernia, 15, 201-203. https://doi.org/10.1007/s10029-009-0624-9

[2] Fenton, L.Z. and McCabe, K.J. (2002) Giant Unilateral Abdominoscrotal Hydrocele. Pediatric Radiology, 32, 882-884. https://doi.org/10.1007/s00247-002-0735-2

[3] Gentile, D.P., Rabinowitz, R. and Hulber, W.C. (1998) Abdominoscrotal Hydrocele in Infancy. Urology, 51, 20-22. https://doi.org/10.1016/S0090-4295(98)00085-5

[4] Cuervo, J.L., Ibarra, H. and Molina, M. (2009) Abdominoscrotal Hydrocele: Its Particular Characteristics. Journal of Pediatric Surgery, 44, 1766-1770.

https://doi.org/10.1016/j.jpedsurg.2008.12.002

[5] Garg, P.K., Prasad, D., Agrawal, V., et al. (2011) Abdominoscrotal Hydrocele: An Insight into Its Orgin. Hernia, 15, 587-589 https://doi.org/10.1007/s10029-010-0703-y

[6] Ferro, F., Lais, A., Orazi, C., et al. (1995) Abdominoscrotal Hydrocele in Childhood: Report of Four Cases and Review of the Literature. Pediatric Surgery International, 10, 276-278. https://doi.org/10.1007/BF00177182

[7] Pogorelic, Z., Juric, Z., Bogdanic, Z., et al. (2013) Bilateral Abdominoscrotal Hydrocele in a 5-Month-Old Infant Presented with a Left Leg Edema and Cyanosis. Hernia, 17, 533-535. https://doi.org/10.1007/s10029-012-0953-y

[8] Blevrakis, E., Anyfantakis, D.I. and Sakellaris, G. (2011) Abdominoscrotal in a 9-Month Old Infant. Hernia, 15, 201-203. https://doi.org/10.1007/s10029-009-0624-9

[9] Estevao-Costa, J., Morgado, H., Soares-Oliveira, M., et al. (2005) Hemorrhagic Abdominoscrotal Hydrocele: A Challenging Entity. Journal of Pediatric Surgery, 40, 731-733. https://doi.org/10.1016/j.jpedsurg.2005.01.012

[10] Velasco, A.L., Ophoven, J. and Priest, J.R. (1988) Paratesticular Malignant Mesothelioma Associated with Abdominoscrotal Hydrocele. Journal of Pediatric Surgery, 23, 1065-1067. https://doi.org/10.1016/S0022-3468(88)80034-4

[11] Vaos, G., Zavras, N. and Eirekat, K. (2014) Testicular Dysmorphism in Infantile Abdominoscrotal Hydrocele: Insights into Etiology. International Urology and Nephrology, 46, 1257-1261. https://doi.org/10.1007/s11255-014-0665-6

[12] Upadhyay, V., Abubacker, M. and Teele, R. (2006) Abdominoscrotal Hydrocele-Is There a Place for Conservative Management? European Journal of Pediatric Surgery, 16, 282-284. https://doi.org/10.1055/s-2006-924343

[13] Celayir, A.C., Akyuz, U., Ciftlik, H., et al. (2001) A Critical Observation about the Pathogenesis of Abdominoscrotal Hydrocele. Journal of Pediatric Surgery, 36, 1028-1084. https://doi.org/10.1053/jpsu.2001.24760

[14] De Renzo, C.C. and Barone, J.G. (2006) Nonoperative Management of Abdominoscrotal 
Hydroceles in an Infant. Urology, 68, 428.e9-11.

https://doi.org/10.1016/j.urology.2006.03.023

[15] Erdener, A., Mevzim, A. and Herek, O. (1992) Abdominoscrotal Hydrocele: Case Report and Review of the Literature. Pediatric Surgery International, 7, 398-400.

https://doi.org/10.1007/BF00176607

Submit or recommend next manuscript to SCIRP and we will provide best service for you:

Accepting pre-submission inquiries through Email, Facebook, LinkedIn, Twitter, etc. A wide selection of journals (inclusive of 9 subjects, more than 200 journals)

Providing 24-hour high-quality service

User-friendly online submission system

Fair and swift peer-review system

Efficient typesetting and proofreading procedure

Display of the result of downloads and visits, as well as the number of cited articles

Maximum dissemination of your research work

Submit your manuscript at: http://papersubmission.scirp.org/

Or contact ojped@scirp.org 